\title{
Energy demand analysis of five star hotel in Nepal- A Case Study of Bhairahawa, Nepal
}

\author{
Shadananda Acharya ${ }^{a, *}$, Shree Raj Shakya ${ }^{a}$ \\ ${ }^{a}$ Department of Mechanical and Aerospace Engineering, Pulchowk Campus, Institute of Engineering, Tribhuvan University, Lalitpur, Nepal
}

\section{ARTICLE INFO}

\section{Article history:}

Received 28 Dec 2020

Received in revised form

05 Feb 2021

Accepted 15 Feb 2021

Keywords:

LEAP

Hotel

Energy mix

Greenhouse gas

Energy Consumption

\begin{abstract}
Tourism sector is one of the most vital sector for economic development. Hotels consumed bulk amount of energy to satisfy the guest needs. This study to development of energy mix concept in the hotels sector to minimize the crisis of energy in the future, determine electrical and thermal energy consumption patterns of a hotel. Low Emission Analysis Platform (LEAP) model was used to analyze energy demand and greenhouse gas emission under different scenarios. The base year for the study was 2019 and the end year up to 2040. It has been estimated that the base year electrical and thermal consumptions were 16.3 Tera joule and 9 tera joule respectively. Energy consumption is expected to be increased from 25.3 tera joule to 65.9 tera joule in 2040 under business as usual scenario (BAU). In efficient lighting scenario, energy consumption will be 2 tera joule in 2040. In efficient heating ventilation and air conditioning scenario, efficient cooking scenario and steam generation scenario, energy consumption will be 12 tera joule, 6.5 tera joule and 4.2 tera joule in 2040 . In combined policy scenario, energy consumption will be 37.76 tera joule in 2040 . Which result saving of 28.14 tera joule as compared to BAU scenario. This study also show the greenhouse gas emission will be 1100 metric tons of carbon dioxide equivalent in 2040 under business as usual scenario. After the implementation of the efficient system, greenhouse gas emissions will gradually reduce and reach zero in 2035 to 2040. Similarly, per capita greenhouse gases emissions will gradually reduce and reach zero in 2035 to 2040. Thus large amount of energy can be saved and large quantity of greenhouse gas emission can be stopped by applying the combined policy scenario.
\end{abstract}

CJIEE Thapathali Campus, IOE, TU. All rights reserved

\section{Introduction}

The tourism industry is one of the most vital sectors for economic development [1].The tourism sector is an important sector for Nepal to generate revenue and foreign exchange. The diversity in nature and culture increase potentiality in the tourism sector. The overall economics of Nepal is very backward so country policies need to be changed to enhance the tourism sector and economic development [2].

Energy consumption in the hotel building depending up on the various factor like local climate condition, location of hotel, types of service standard along with occupancy situation and the equipment efficiency [3]. According to the study, energy intensity depends up on

\footnotetext{
*Corresponding author:

@achshada@gmail.com (S. Acharya)
}

various factors like climate condition and occupancy rate. [4]. Total Gross value added of the hotel and restaurant sector is expected to stand $8.3 \%$ in the financial year $2018 / 219$ where as $9.8 \%$ was in the financial year 2017/2018. Hotel and restaurant sector contribute $2.1 \%$ of the total GDP in the financial year 2018/2019. [5]. Per capita GDP of Nepal is $\$ 1034$ in the financial year 2018/219 whereas per capita GDP was $\$ 998$ in the financial year 2017/2018 [5]. According to ADB study, Final energy demand will increase $1.9 \%$ annually through 2035 and 3.7\% GDP growth rate projected for the same period [6].

Hotel sector is an important sector of tourism industry in Nepal. Hotels spent lots of energy to satisfy the guest needs while guest stay inside the hotels but many energy losses from the system due to lack of energy managing practice in a hotel sectors. This is due to the lack of practice of energy audits in hotel, lack of knowledge 
in the energy management system and lack of information about the latest energy efficient technology for hotel energy management, lack of practice to checked and maintain major equipment standby mode [7]. After the analysis of energy-related data, the next phase is calculating the data and the target area is to be select for minimizing energy consumption and finally future planning needs to keep on the system [8]. The energy demand analysis of a hotel helps to find out the present energy consumption by end use sector, electrical and thermal energy consumption patterns of a hotel. Baseline data can be helps to support for the energy demand analysis in a hotel. For this analysis, different scenarios were developed for the end use sector and analyze the data by using LEAP software. The energy demand analysis is also forecast the prediction of future total energy demand, end use energy demand, electrical and thermal energy consumptions and energy mix patterns. This study helps to find out the selection of the efficient technology and strategies for the sustainable development of the hotel sectors.

\section{Research Methodology}

The study is carried out according to the research framework as shown in Figure 1. The study framework consists of issue identification and research question related to star hotel energy performance, analytical model development, Scenario development and analysis, and analysis of occupancy effects as well. The principle methodology for the study is primary data collection and many questionnaires were developed and survey was carried out on hotel. The survey data was used in the computer by using LEAP software.

\subsection{LEAP software}

LEAP model is a static energy- economy-environmental model which has been used software for energy policy analysis in the future. The leap model can be used to calculate energy requirements, transformation and energy sources. The modeling method in leap is accounting method. Energy demand and supply can be calculated by this method. LEAP provides four major which used in energy modeling. This four are key assumptions, demand, transformation and resources [9].LEAP is forecasting software which helps to analysis the current energy scenario and forecast for future under certain condition.

\subsubsection{LEAP Model Scenario Description Study Parameters and Assumptions / Constraints}

This study was based on the number of parameter and assumptions. These mainly covered the technical and economic aspects descried in details and were used as

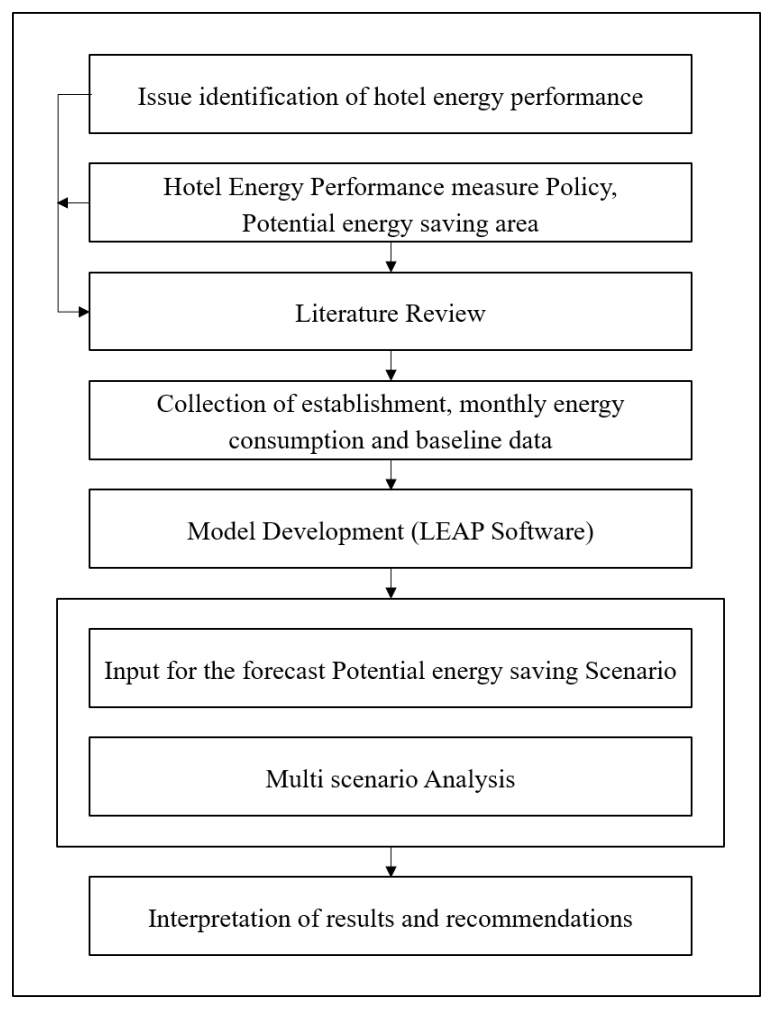

Figure 1: Research Framework of the study

input to LEAP.

\section{Key Parameters}

For completion of this study: - the base year was 2019, demand, historical data for analysis, technologies for electricity generation and other trend were taken as the key parameters. Different variable are consider while doing the research i.e GDP, GDP growth, occupancy, occupancy growth and system loses etc.

\subsubsection{Study Period}

Twenty year plan for this study in the year 2021 to 2040 meet the target. The prediction of the results reference year was 2019

\subsubsection{Field Survey}

The field visit was done on sample hotel which is located at Bhairahawa, Lumbini.

\section{Modeling}

LEAP model was used for future energy planning purpose. Data was collected from field visit and fed data into LEAP model. The base year for the study was 2019 and the tree structure of the LEAP model is shown in Figure 2. 
Energy demand analysis of five star hotel in Nepal- A Case Study of Bhairahawa, Nepal

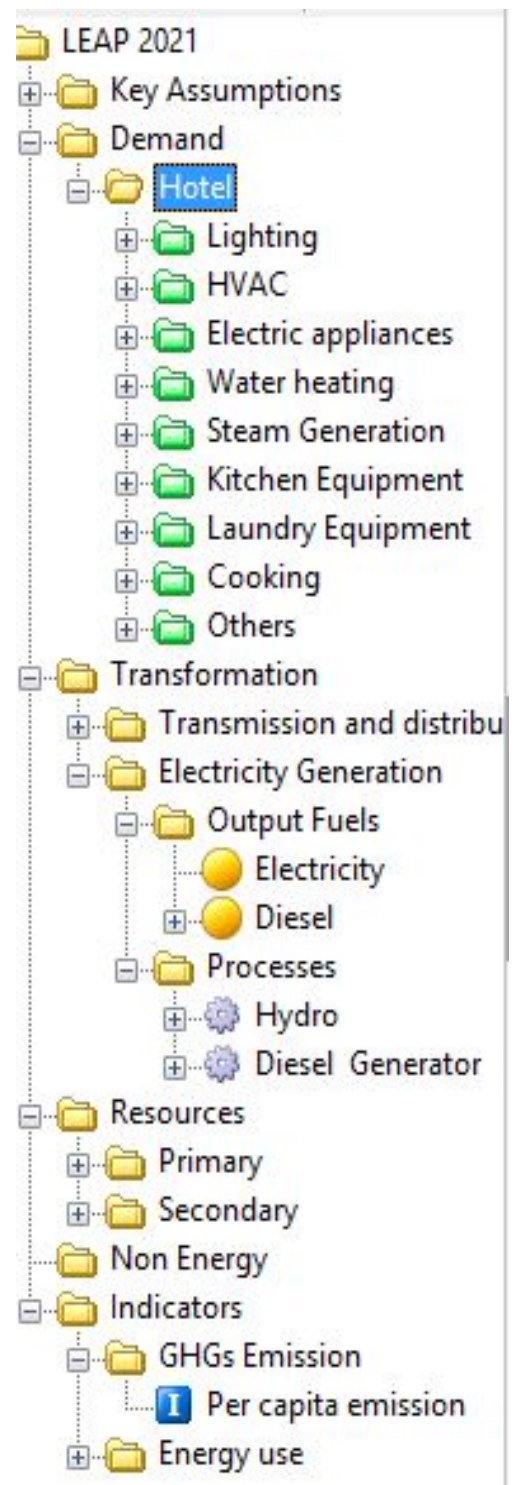

Figure 2: LEAP Tree

\subsubsection{Energy Demand Projection}

For the energy demand analysis, 2019 was the base year, tourist arrival and GDP per capita is taken as the variable for the energy demand projection. The regression analysis was used for the relationship between tourist arrival in selected area, GDP per capita and energy service demand per capita for different subsector is achieved using the Eq. 1 [10].

$$
\frac{\mathrm{ESD}_{i, t}}{\mathrm{ESD}_{0}}=\left(\frac{\mathrm{NOT}_{t}}{\mathrm{NOT}}\right)^{\alpha i} \times\left(\frac{\mathrm{GDP}_{t}}{\mathrm{GDP}_{0}}\right)^{\beta i}
$$

Where,

$\mathrm{ESD}_{0}$ : Energy Service Demand per capita for sub sector ' $i$ ' in base year

$\mathrm{ESD}_{t}$ : Energy Service Demand per capita for sub sector ' $i$ ' in year $t$

$\mathrm{GDP}_{0}:$ GDP per capita for base year

$\mathrm{GDP}_{t}$ : GDP per capita for subsector ' $\mathrm{i}$ ' in year $\mathrm{t}$

$\mathrm{NOT}_{0}:$ Number of tourist arrival in the base year

$\mathrm{NOT}_{t}$ : Number of tourist arrival for subsector ' $i$ ' in year $\mathrm{t}$

\subsection{Scenario analysis}

\subsubsection{Business as Usual Scenario}

Business as usual scenario is that tool that is used for project thetotal rooms use into the future under the assumption of the growth of the hotel room in the future. Table 1 show the number of available room and occupied room for the year 2018 and 2019.

Table 1: Number of available room, total occupied room and occupancy

\begin{tabular}{lll}
\hline Year & No. of available rooms & Occupancy rate \\
\hline 2018 & 102 & $53.92 \%$ \\
2019 & 102 & $60.00 \%$ \\
\hline
\end{tabular}

Total available room in the sample hotel was 102 rooms in the base year 2019 and numbers of room will increase as per organizational policy. Fixed values were for the room capacity; 102 in year 2019,180 room in 2026, 300 rooms in 2030 and 400 rooms in 2040. Percentage share and occupancy rate for the year 2019 were studied from the data sheet and future trends was forecasted as the growth rate. It is the base case scenario which helps to find base year energy demand according to reference data and demand trend will continue for the future with no intervention. For this scenario analysis, the value of tourist arrival growth and GDP growth is taken as the average growth in the past ten years. End-use technologies are not changed in this scenario. In this scenario GDP growth are taken $2 \%$ as per the past average tourism growth rate on national GDP [11]. Tourist arrival growth consider the $3 \%$ as per the average tourist forecasted on future [12]

Energy intensity of hotel fed into the model under electricity, diesel, LPG and fuel oil. LEAP was used to calculate the total energy consumption by multiplying the energy intensity of hotel by each activity level, occupancy rate and capacity of the room increase from 2019 to 2040

\subsubsection{Combined policy scenario}

The purpose of combined policy scenario is to reduce energy consumption by end-use sector. From the kitchen, 
a lot of waste may be generated which can be used for biogas generation and used for cooking purposes [13]. In this scenario, replacement of all the traditional fuels like LPG, coal and diesel by clean energy like electricity, promotion of electricity in all the subsection to eliminate emissions and intervention through more efficient system [14].

\section{Generator Replacement Scenario}

This is a supply side management scenario. In the sample hotel, $23.08 \%$ of the total energy was generated by DG in the year 2018 and which was down and reach to only $8.81 \%$ of the total energy was generated by the DG in the year 2019. In the context of Nepal, most of the electricity came from hydropower where 1029.58MW electricity produced by hydropower and only $53.4 \mathrm{MW}$ electricity generated by thermal system which per-unit cost is higher than hydropower. Many hydro powers are under construction, planned and proposed in Nepal so it is possible to replace DG by grid electricity. According to NEA data, 957.1 MW capacity hydropower are under construction, planned and proposed hydropower capacity are 2285.2 MW and there is also $25622 \mathrm{MW}$ hydropower are also planned and proposed of the government of Nepal so no power deficiency in near future. NEA started the high voltage transmission lines and many of them are under construction i.e total $805 \mathrm{KM}$ length circuit of $132 \mathrm{kV}$ transmission line will be completed on 2021/2022, $630 \mathrm{KM}$ length circuit of $220 \mathrm{kV}$ transmission line will be completed on 2021/2022 and $576 \mathrm{KM}$ length circuit of 400kV Transmission line will be completed on 2020/2021 [15] so near in future voltage stability and transmission line losses will be less than now.

\section{Efficient Lighting Scenario}

Efficient lighting system means use of the more efficiency lighting system i.e replacement of CFL by LED, which helps to reduce the energy consumption [16]. Efficient lighting system helps to save health, safety, comfort and productivity [17]. In the base year, $4.55 \%$ total energy consume through lighting system. In the hotel, most of the light was LED and which share $80 \%$ of total lighting and remaining 20\% was through CFL. In this efficient scenario, it was assumed that by 2026, all the CFL light will be replaced by LED light.

\section{Efficient Cooking Scenario}

The device is generally the most efficient device which heat up fast and cook food fast. The efficiency of LPG stove is $68 \%$ while using brass burner for cooking purpose and efficiency of LPG cooking stove is $64 \%$ while using cast iron burner for cooking purpose [18]. Recently, induction base cooking stove is introduced in market but lack of practice for cooking system. The efficiency of induction cooking stove is $90 \%$ [19]. From above analysis, the efficiency of induction base cooking stove is more than LPG base cooking stove. In Nepal, recently NEA promote use of electricity for cooking purpose and NEA focus on subsidy while use more electricity. Many hydro-powers are being introduced in Nepal so near in future the availability of electricity is high. But the government needs to be change policy to promote use of electricity in Nepal because most of houses energy meter in Nepal is low ampere rating like $5 \mathrm{~A} / 6 \mathrm{~A}$ rating so the government and NEA body has to promote minimum $16 \mathrm{~A}$ rating energy meter with induction cooking system from subsidy. On the other hand, LPG is not self-produced by the government it is imported source of fuel for Nepal and which does not have its reserve so near in future used of LPG for cooking is expensive and market may be shortage so use of LPG for cooking is more expensive than induction base cooking system. The government body has to remove subsidy for LPG and promote electricity.

Table 2: Monthly life cycle cost of different fuels [20].

\begin{tabular}{llll}
\hline \multicolumn{4}{c}{ Fuel cost per month per technology } \\
Year & Kerosene Price & LPG Price & Electricity tarrif \\
\hline 2000 & 289 & 550 & 630 \\
2003 & 476 & 700 & 730 \\
2006 & 816 & 900 & 730 \\
2011 & 1249.5 & 1325 & 730 \\
2012 & 1581 & 1415 & 875 \\
2018 & 1411 & 1375 & 1050 \\
\hline
\end{tabular}

The cost of kerosene, LPG and electricity from the year 2000 to 2018 has shown in Table 2. In the hotel, only $1 \%$ of cooking system was used from electricity in the year 2019 but in future, policy need to be change by management team and it is better efficient system when cooking system from electricity rather than cooking by LPG so it was assumed that for efficient cooking system, 100\% of the coal consumption will be replaced by electricity by the year 2026 and by 2030 60\% LPG base cooking system will be replaced by electric base induction system and by 2035, 100\% LPG base cooking system will be replaced induction base electric system.

\section{Efficient Steam Generation scenario}

The operating principle of efficient boiler is that which can generate steam when heat from flue gases to pre heat the feed water or reuse of losses steam to increase the temperature of boiler [21]. The efficiency of boiler in the sample hotel was $76.98 \%$ while feed water temperature is $20^{\circ} \mathrm{C}$ and lots of steam was losses from the system i.e no provision for return use of steam in the hotel. When proper reuse of steam, the boiler efficiency reaches to $86.89 \%$ while the feed water temperature is 
$85^{\circ} \mathrm{C}$. According to study, boiler efficiency can be reach up to $89.66 \%$ [22]. In this efficient scenario, boiler efficiency will improve to $85 \%$ by 2023 and $89.66 \%$ by 2030. This improved on boiler efficiency can reduce consumption of diesel in the hotel. It was assumed that, $70 \%$ steam will be generate from electric boiler by 2030 and $100 \%$ steam will be generate from electric boiler by 2035.

\section{Efficient Heating Scenario}

In the hotel, heat pumps are used for the purpose of water heating system that means $100 \%$ hot water heating system from the heat pumps which consumed electricity but for the space heating, VRF and chiller was used in hotel for two/three weeks in winter. More advantage from heat pump for water heating than water heating from boiler system because in the heat pump system the heat transferred can be much greater than the electricity required to driver the cycle. In mostly used heat pump system heat is extracted from ambient air which is then transferred to water which is then stored within a hot water cylinder. In this system, number of energy flows into and out of the system where electrical energy is input for the system to run a heat pump cycle and environmental heat is also input for the system to heat water and some energy being losses to the surrounding.

\section{Efficient Air conditioning Scenario}

Air condition efficiency ratio is measured according to energy efficiency ratio (EER), which is ratio of cooling capacity of system to the input power of the system and more efficient the air conditioner when EER rating is high. In efficient air conditioning system, variable speed compressors and advance control systems can improve efficiency of the system. [23]. In the hotel, most of the area air conditioning system maintains by central air conditioners but some area split AC was used, ceiling cassette AC and guest room area VRF system was used. According to study, VRF system provides more average temperature than another system. VRF systems save up to $35 \%$ energy than chiller system under the tropical climate condition [24]. The performance analysis of VRF and chiller are different but based on the COP, average COP of VRF was 4.2, 3.9 and 3.7 under the $100 \%, 75 \%$ and $50 \%$ load respectively. Similarly, COP was 3.1, 3 and 2.5 of the Chiller system while system load are 100\%, 75\% and 50\% load respectively [25]. It was assumed that $50 \%$ of HVAC system will be operate by chiller system on 2026 and $25 \%$ of system load will be operate from chiller system by 2030 and only $25 \%$ of total load will be operate from chiller system by 2035. Similarly, $40 \%$ of total load will be operate from VRF system by 2026 and $60 \%$ and $80 \%$ of total load will be operate from VRF system by 2030 and 2040 respectively.

\section{Result and discussion}

\subsection{Base year Energy Consumption Analysis}

The total energy consumption in the hotel is calculated according to fuels used and end use sector. Figure 3 the energy share of different end use sector in the base year 2019. From the figure, end use sector share of HVAC system was the highest share among the other end use sector i.e $39.1 \%$ share. The second highest share was cooking sector whose was $19.9 \%$ which is then followed by electric appliance and steam generation i.e $11.1 \%$ and $10.9 \%$ respectively and laundry equipment consumed the lowest energy than other remaining system i.e $1.2 \%$.

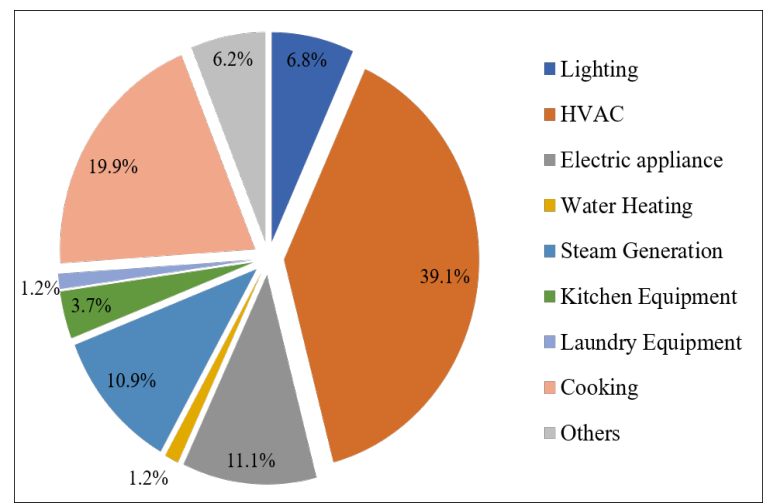

Figure 3: Base year energy share for end use sector

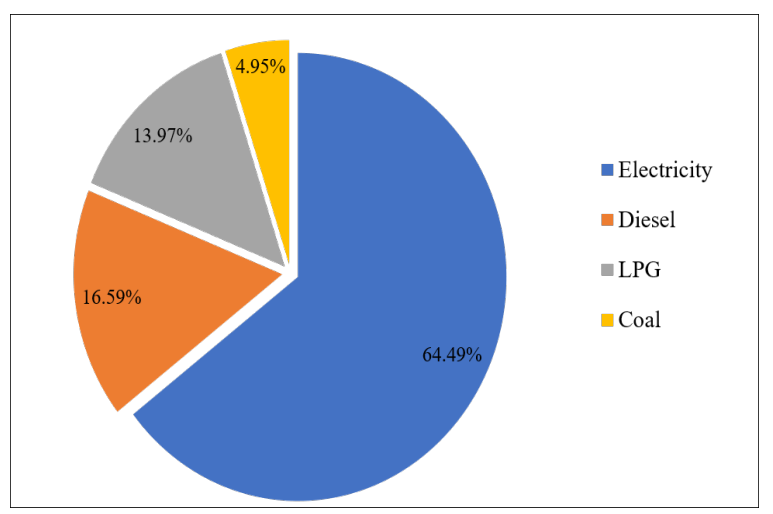

Figure 4: Base Year energy share of different fuels 2019

The Figure 4 show the share of different fuels in hotel where grid electricity share was highest among other i.e $64.49 \%$ energy was generated from electricity which is then followed by the diesel whose share was $16.59 \%$ which was the second highest among the other. The share of LPG and coal was $13.97 \%$ and $4.95 \%$ respectively. The figure 4 clearly show that the total energy 
share of electricity was $64.49 \%$ and remaining $35.51 \%$ share was from fossil fuels which emit environmental pollution.

\subsection{Final Energy Demand}

\subsubsection{Business as usual Scenario}

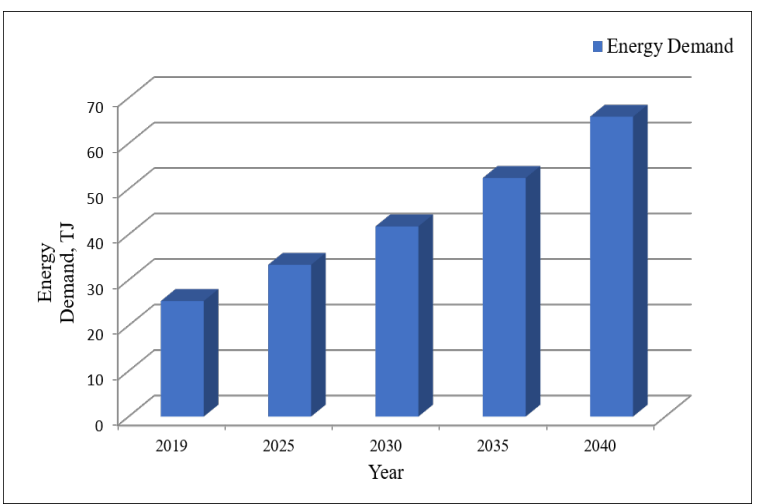

Figure 5: Total Energy Demand, (TJ) under business as usual scenario

The Figure 5 the total energy demands of a hotel in different years. In base year, 25.7 TJ energy was consumed in hotel and energy consumption is expected to be increased from $25.7 \mathrm{TJ}$ to $65.9 \mathrm{TJ}$ in 2040 under business as usual scenario. It has been estimated that, electrical energy and thermal consumptions were 16.3 TJ and 9 TJ respectively in 2019. Energy consumption can validate from energy use intensity (EUI) of the hotel. Here are some comparisons for EUI of different hotels which is vary according to occupancy, location of hotel, local temperature, year of building construction and so on. Average EUI of hotel was in between 69 to 689 $\mathrm{Kwhr} / \mathrm{m}^{2} /$ year [26]. Average EUI of hotels in shanghai was $704.38 \mathrm{Kwhr} / \mathrm{m}^{2} /$ year [27].

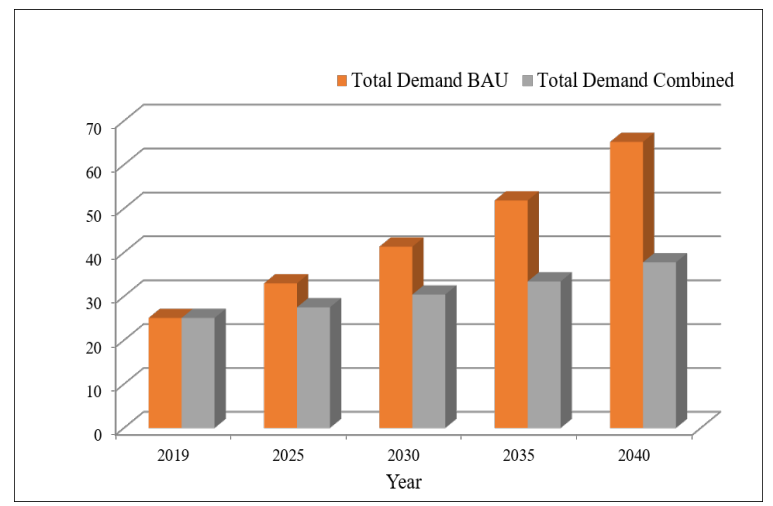

Figure 6: Total energy demand (TJ) under BAU and Combined policy Scenario

\subsubsection{Energy Saving Potential}

The Figure 7 shows the potential of energy saving after the implementation of efficient scenario in the hotel. Energy consumption can be reduced only when the replacement of LPG, coal and diesel by electricity. Figure 7 show the 3.3 tera joule energy will save in 2022 and which is expected to be increased and reach 27 tera joule in 2040. Similar study shows that, total 203 tera joule energy can be save from hotel [28] and another study also explain the total 79 tera joule energy will save in 2025 in five and four star hotel in Kathmandu [29] that why future energy saving potential validated from this report.

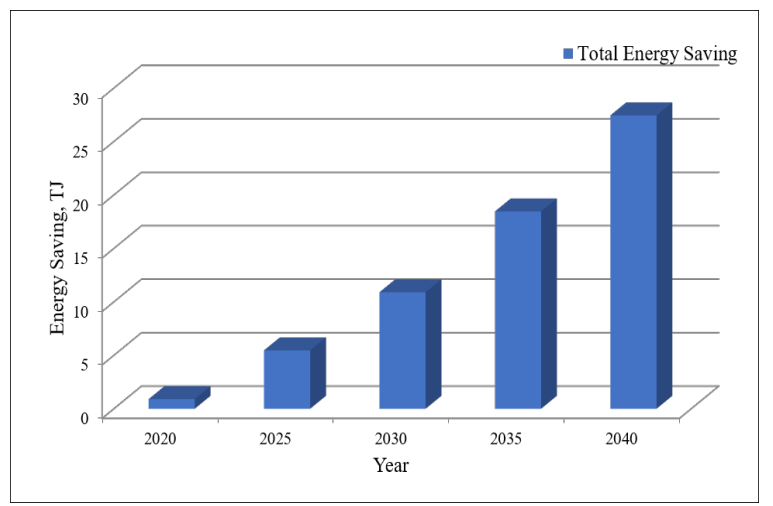

Figure 7: Total energy saving (TJ) after implementation of combined policy scenario

\section{Lighting Scenario}

The Figure 8 shows the total energy consumption under business as usual (BAU) lighting system and efficient lighting system. Figure 8 show the 1.73 tera joule energy was consumed in 2019 and energy consumption is expected to increase and reach 3.96 tera joule in 2040 under business as usual scenario. After implementation of efficient lighting system, energy consumption will reach only 2.64 tera joule in 2040 so 1.3 tera joule energy will be save in 2040 from efficient lighting system.

\section{HVAC scenario}

Figure 9 shows the total energy consumption under business as usual (BAU) HVAC system and efficient HVAC system. Figure 9: show the 9.9 tera joule energy was consumed in 2019 and energy consumption is expected to increase and reach 22.6 tera joule in 2040 under business as usual scenario. After implementation of efficient HVAC system, energy consumption will reach only 12.8 tera joule in 2040 so 9.8 tera joule energy will be save in 2040 from efficient HVAC system.

\section{Cooking scenario}

Figure 10 shows the total energy consumption under business as usual (BAU) cooking system and efficient 


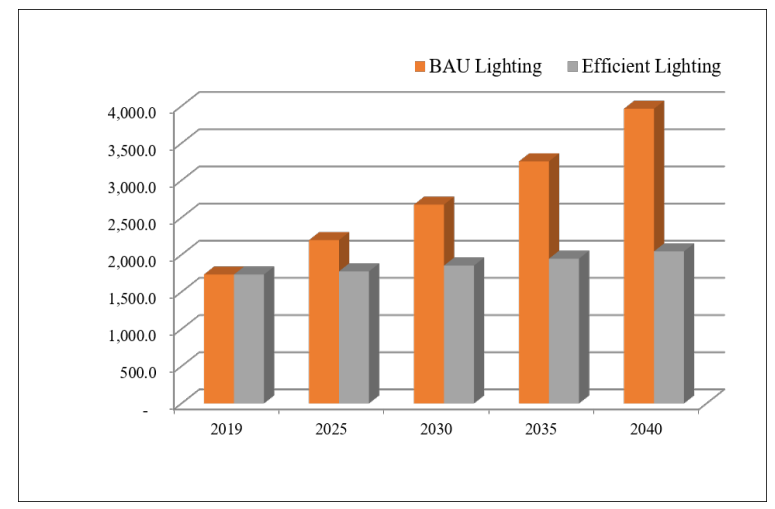

Figure 8: Energy demand (GJ) under different lighting scenario

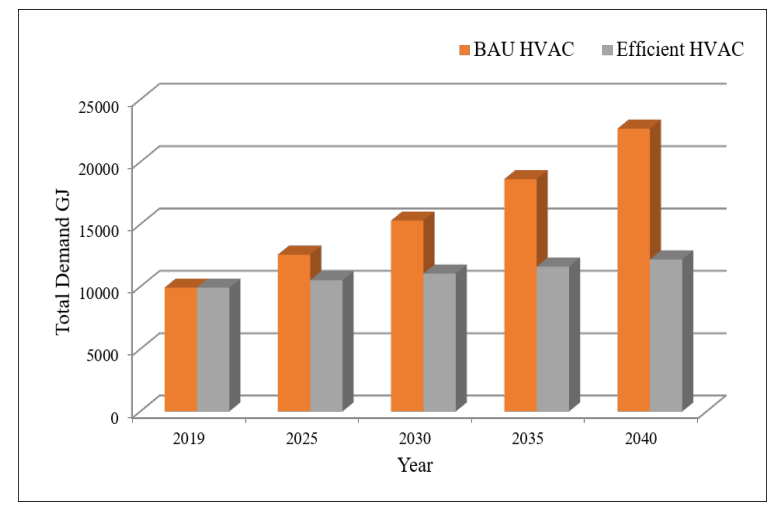

Figure 9: Energy demand (GJ) under different HVAC scenario

cooking system. Figure 10: show the 5 tera joule energy was consumed in 2019 and energy consumption is expected to be increase and reach 16.5 tera joule in 2040 under business as usual scenario. After implementation of efficient cooking system, energy consumption will reach only 6.5 tera joule in 2040 so 10 tera joule energy will be save in 2040 from efficient cooking system.

\section{Steam Generation Scenario}

Figure 11 shows the total energy consumption under business as usual (BAU) steam generation system and efficient steam generation system. Figure 11 shows the 2.7 tera joule energy was consumed in 2019 and energy consumption is expected to be increase and reach 9.2 tera joule in 2040 under business as usual scenario. After implementation of efficient steam system, energy consumption will reach only 4.2 tera joule in 2040 so 4.9 tera joule energy will be save in 2040 from efficient cooking system.

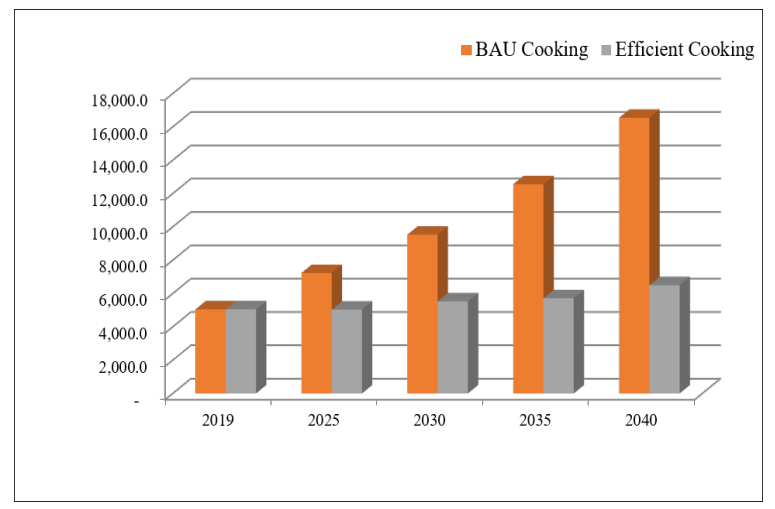

Figure 10: Energy demand (GJ) under different Cooking scenario

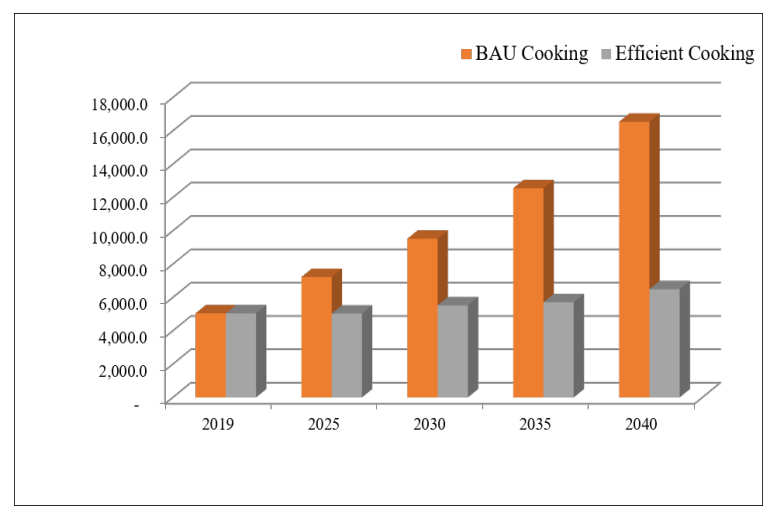

Figure 11: Energy demand (GJ) under different Steam Generation scenario

\section{Conclusions}

The necessary calculations were made by using the measurement and existing meter values and all the necessary value are fed into LEAP software for energy measurement. Calculated data show that, 25.3TJ energy was consumed in 2019 where as 9 TJ energy was produced from thermal energy and remaining $16.3 \mathrm{TJ}$ energy was produced from grid electricity. Energy consumption is expected to be increased from 25.3 TJ to 65.9 thousand GJ in 2040 under business as usual scenario. In combined policy scenario, energy consumption is expected to increase from $25.3 \mathrm{TJ}$ to $37.76 \mathrm{TJ}$ in 2040 under combined policy scenario and $3.3 \mathrm{TJ}$ energy will save in 2022 and which is expected to be increased and reach $27 \mathrm{TJ}$ in 2040 from combined policy scenario. In efficient lighting scenario, energy consumption will reach only $2.64 \mathrm{TJ}$ in 2040 so $1.3 \mathrm{TJ}$ energy will be save in 2040 from efficient lighting system. After the implementation of efficient HVAC system, energy consumption will reach only $12.8 \mathrm{TJ}$ in 2040 so $9.8 \mathrm{TJ}$ energy will be save in 2040 from efficient HVAC sys- 
tem. After implementation of efficient cooking system, energy consumption will reach only $6.5 \mathrm{TJ}$ in 2040 so $10 \mathrm{TJ}$ energy will be save in 2040 from efficient cooking system. After implementation of efficient steam system, energy consumption will reach only $4.2 \mathrm{TJ}$ in 2040 so 4.9 TJ energy will be save in 2040 from efficient cooking system.

\section{Recommendation}

Cost and energy needed for electricity generation from diesel generator system is high as compared to the hydroelectric, thus use of hydroelectric should be promoted in hotel. LPG, coal and diesel leads to increase greenhouse gas emission so replacement of fuel base appliance by electric appliance should be promoted in hotel. Biogas can be produced from kitchen waste so installation of biogas plant leads to make hotel less dependent on fossil fuels. Boiler feed water temperature was low and lots of steam losses while steam was used in laundry purpose so feed water temperature can be increased by utilizing of losses steam and fuel required for steam generation can be reduce so greenhouse gas emission also reduced but it is more efficient when steam will generate from electricity. Details energy audit should be carried out to identify the potential energy saving area in hotel.

\section{Acknowledgement}

I would like to express my deepest gratitude towards thesis supervisors-professors for their timely suggestions and guidance's. This thesis would not have been possible without his assistance and encouragement. I would like to thank Mr. Rajan Sharma, Sagaun Paudyal and Rabi Sapkota for their valuable idea of the topics and suggestion throughout the research period. Also, I would like to express my gratitude toward the entire department faculties, whose valuable comment and suggestion were very important for the thesis work. Last but not the least, special thanks go to the editor and the reviewers of this research paper for their comments to write this paper.

\section{References}

[1] Bodach S, Lang W, Auer T. Design guidelines for energyefficient hotels in Nepal[J/OL]. International Journal of Sustainable Built Environment, 2016, 5(2): 411-434. DOI: https: //www.doi.org/10.1016/j.ijsbe.2016.05.008.

[2] Basnet S. Types of tourism in Nepal and their prospect[R/OL]. Kerava, 2016: 1- 47. https: //www.theseus.fi/bitstream/handle/10024/115568/Tourismand-Prospect-Thesis-Report.pdf?sequence $=1$.

[3] Bohdanowicz P, Martinac I. Determinants and benchmarking of resource consumption in hotels-Case study of Hilton International and Scandic in Europe[J/OL]. Energy and Buildings, 2007, 39(1): 82-95. DOI: https://www.doi.org/10.1016/ j.enbuild.2006.05.005.
[4] CBS. Nepal - Survey of Hotels and Lodges Nepal 200304[R/OL]. Kathmandu, Nepal: National Planning Commission of Nepal, 2004: 1-18. http://cbs.gov.np/nada/index.php/catalog/ 20.

[5] Ministry of Finance. Economic Survey of Nepal 2018/2019[R]. Kathmandu, Nepal: Government of Nepal, 2019.

[6] Asian Development Bank. Nepal Energy Sector Assessment, Strategy and Road Map[R]. 2017.

[7] PACE Nepal Pvt.Ltd. Baseline Study of Selected Sector Industries to assess[R]. 2012.

[8] Ishak N B. Energy Management Practices and Implementation in Campus Building $[\mathrm{J}]$. Master Thesis,Faculty of Engineering Technology ,University Malaysia Pahang, 2016(March).

[9] Windarta J, Purwanggono B, Hidayanto F. Application of LEAP model on long-term electricity demand forecasting in Indonesia, period 2010-2025[J/OL]. SHS Web of Conferences, 2018, 49: 02007. DOI: https://www.doi.org/10.1051/shsconf/ 20184902007.

[10] Prem S, Shree Raj S. Energy Efficiency and Low Carbon Strategy on Rural Tourism Area: A Case of Mount Annapurna Trekking Route[J/OL]. International Journal of Environmental Protection and Policy, 2016, 4 (5): 133. http://www.sciencepublishinggroup.com/journal/ paperinfo?journalid=266. DOI: https://www.doi.org/10.11648/ j.ijepp.20160405.14.

[11] Ministry of Finanace. Economic survey of Nepal 2019/20[R]. Kathmandu, Nepal: Government of Nepal, 2020.

[12] Ministry of Culture T, Aviation C. Nepal Tourism Statistics 2018[R]. Kathmandu, Nepal: Government of Nepal, 2019.

[13] Amarawardhana K. modeling of the energy utilization of tourism industry to predict the future energy demand to shower case of Sri lanka[J]. 2010.

[14] Central Department of Enviromental Science (CDES ). Nepal's GHG Inventory[R]. Tribhuvan University, 2017.

[15] Nepal Electricity Authority. A year in Review Fiscal year 2018/2019[R]. Kathmandu, Nepal: Government of Nepal, 2019.

[16] Guzzetti S, Faranda R, Lev S. Design and Technology for Efficient Lighting System[J/OL]. Paths to Sustainable Energy, 2010. DOI: https://www.doi.org/10.5772/13326.

[17] lorin POP and Horia F. POP. Residential Energy Efficient Lighting $[\mathrm{C}] / /$ 2nd International Conference On Modern Power Systems. 2008.

[18] Yadav D s. Performance analysis of LPG cok stoves with modifications $[\mathrm{C}] / /$ Interntional conference on recent innovations and developments in mechanical engineering. Shilong India, 2018.

[19] Ugye R, Kolade A, Abdullahi A J. Comparative Studies of Cooking Fuels and the Need to Harness Induction Cooking: South Africa as a Case Study[J/OL]. American Journal of Engineering Research (AJER, 2019(8): 155-161. www.ajer.org.

[20] Amrit N. Monthly life cycle cost of cooking with different fuels[Z]. 2018.

[21] Satyavada H, Baldi S. Monitoring energy efficiency of condensing boilers via hybrid first-principle modelling and estimation[J/OL]. Energy, 2018, 142: 121-129. DOI: https: //www.doi.org/10.1016/j.energy.2017.09.124.

[22] Kilinc E. Investigation of Overall Efficiency Improvements and Saving Opportunities for an Industrial Boiler[J]. karabuk, 2018 (April).

[23] Bansal P. High Efficiency Room Air Conditioner[J/OL]. 2015. http://www.ntis.gov/help/ordermethods.aspx \{\%\}0Ahttp: //www.osti.gov/contact.html.

[24] Yu X, Yan D, Sun K, et al. Comparative study of the cooling energy performance of variable refrigerant flow systems and variable air volume systems in office buildings[J/OL]. Applied Energy, 2016, 183: 725-736. DOI: https://www.doi.org/ 10.1016/j.apenergy.2016.09.033.

[25] Piljae Im, Mini Malhotra J D M. Evaluation of VRF systems performance on Oak Ridge National Laboratory's Flexible research 
Energy demand analysis of five star hotel in Nepal- A Case Study of Bhairahawa, Nepal

plateform:- part 1 cooling season analysis[R]. 2016.

[26] Wang J C. A study on the energy performance of school buildings in Taiwan[J/OL]. Energy and Buildings, 2016, 133: 810822. DOI: https://www.doi.org/10.1016/j.enbuild.2016.10.036.

[27] Yao Z, Zhuang Z, Gu W. Study on Energy Use Characteristics of Hotel Buildings in Shanghai[C/OL]// Procedia Engineering: volume 121. 2015: 1977-1982. DOI: https://www.doi.org/ 10.1016/j.proeng.2015.09.195.

[28] NEEP/GIZ, NTNC. Baseline Study of Selected Sector Industries to assess The Potentials for more Efficient use of Energy: February[R]. 2012: 29-36.

[29] Shiva Raj T, Rabindra Nath B, Bhisma P. Energy Demand Analysis of a Sample of Five and Four Star Hotels in Kathmandu Valley[C]// IOE Graduate Conference, 2015. 2015: 273-280. 